\title{
Grupo de encontro com mulheres vítimas de violência intrafamiliar
}

\author{
Virginia Moreira
}

Universidad de Santiago de Chile

\begin{abstract}
Resumo
Este artigo discute a indicação do Grupo de Encontro como uma modalidade de intervenção psicológica na área de saúde pública, descrevendo sucintamente uma pesquisa realizada sobre a aplicação do grupo de encontro no Programa de Maus Tratos à Mulher, desenvolvido pelo Consultorio Externo da Escuela de Psicología da Pontificia Universidad Católica de Chile. Utilizou-se uma metodologia fenomenológica para análise das sessões gravadas em vídeo. Os resultados mostraram que o conteúdo emergente trabalhado nas sessões referiu-se basicamente aos temas relacionados ao mau trato da mulher e às estratégias de superação desta situação, comprovando-se a hipótese da adequação do grupo de encontro em saúde pública no tratamento da violência intrafamiliar.
\end{abstract}

Palavras-chave:

violência

intrafamiliar,

grupo de

encontro,

mulheres

\begin{abstract}
Encounter group with women victims of intrafamiliar violence This article discusses the Encounter Group as a psychological intervention in the public health area. It shortly describes a research and its aplication in the Domestic Violence Program mantained by the Consultorio Externo of the Escuela de Psicología at Pontificia Universidad Católica de Chile. It used a phenomenological method to analyse
\end{abstract}




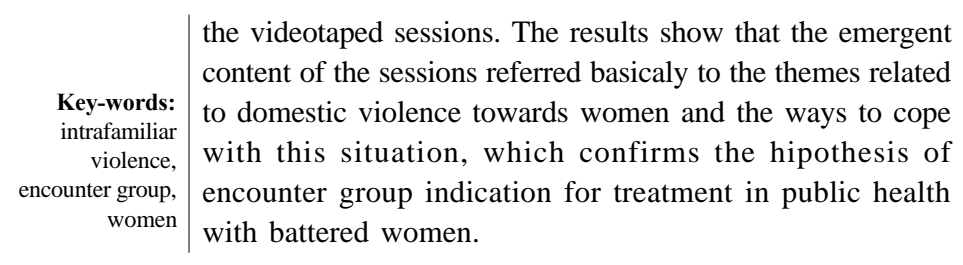

atenção dos profissionais de Psicologia volta-se para saúde
pública, tendo em vista a necessidade de uma intervenção
psicológica não apenas no âmbito do tratamento como da prevenção; mais em termos da problemática psicossocial que propriamente psíquica. Esta é uma necessidade premente nos países da América Latina, onde existe tanta carência em termos de saúde.

Este artigo propõe o grupo de encontro como uma modalidade de intervenção psicológica na área de saúde pública. Descreve sucintamente uma pesquisa realizada sobre a indicação de grupo de encontro no Programa de Maus Tratos a Mulheres, desenvolvido no Consultorio Externo da Escuela de Psicología da Pontifícia Universidad Católica de Chile.

O objetivo desta experiência foi contribuir para o Programa demonstrando a utilização da técnica de intervenção de grupo de encontro, verificando especificamente sua adequação na terapêutica da violência intrafamiliar. Foram realizadas sete sessões com um grupo de oito mulheres, encaminhadas pela equipe de profissionais do Programa, a partir da entrevista inicial realizada no hospital da comunidade. As sessões foram gravadas em vídeo, para posterior análise e discussão com a equipe sobre a indicação dessa modalidade de trabalho no Programa de Maus Tratos.

Em termos técnicos e teóricos, manteve-se a proposta original do grupo de encontro: trabalhar a partir do conteúdo emergente. A hipótese a ser verificada era a adequação desta modalidade de traba- 
lho à temática específica do mau trato, sem que este conteúdo fosse preestabelecido pelas facilitadoras. Acreditava-se que, pelo fato de o grupo reunir pessoas com características comuns - no caso, a violência intrafamiliar -, esta problemática seria expressada e trabalhada enquanto conteúdo emergente do grupo sob condições facilitadoras que propiciassem um clima de confiança para a ocorrência do encontro em um espaço seguro para a auto-expressão e troca de experiências.

\section{Contextualização da experiência: o Programa}

O Programa de Maus Tratos à Mulheres foi desenvolvido em San Bernardo, uma cidade de 200.000 habitantes, na periferia de Santiago, Chile. Sua base teórica foi o modelo de bem estar psicossocial, que enfatiza a competência do indivíduo e da comunidade como recurso na resolução de problemas. O Programa tinha como objetivo inserir-se na comunidade, intervindo em diferentes níveis de prevenção. Neste modelo a equipe profissional tem a função de sistema de suporte para grupos e instituições, trabalhando diretamente com a violência familiar na comunidade através de instituições como hospital, escola, polícia do bairro etc.

O Programa de Maus Tratos foi desenvolvido pela equipe multidisciplinar do Consultorio Externo da Escuela de Psicología da Pontifícia Universidad Católica de Chile, formada por psicólogos, psiquiatras, neurologista e fonoaudiólogo, que trabalharam coordenados em dois subgrupos: um com crianças e outro com mulheres vítimas de violência intrafamiliar.

Os objetivos gerais do Programa foram:

1. sensibilizar membros da comunidade a respeito do problema da violência doméstica, incluindo crianças e mulheres agredidas no lar;

2. identificar possíveis organizações na comunidade que ofereçam suporte, assistência e educação com respeito à violência doméstica;

3. ativar redes intermediárias da comunidade para dar suporte e assistência às vítimas de violência doméstica.

As intervenções foram planejadas considerando-se três níveis de prevenção: primária, secundária e terciária. As atividades de prevenção terciária incluíram intervenção em crise, atendimento psico- 
lógico e encaminhamento das vítimas de violência doméstica a serviços especializados. Estas atividades foram realizadas no hospital local e no consultório psicológico da universidade. $\mathrm{O}$ atendimento psicológico focalizou indivíduos (mulheres e crianças), casais, famílias e redes sociais primárias. As atividades de prevenção secundária incluíram intervenções em crise, grupos de treinamento, supervisão e ativação de grupos de auto-ajuda. O foco desta atividade foi o Sistema de Saúde, o Sistema Educacional, o Sistema Judiciário da Comunidade, o Serviço de Atendimento à Mulher e grupos da comunidade. As atividades de intervenção primária incluíram sensibilização de diferentes grupos, treinamento de monitores em programas de prevenção, planejamento de programas de prevenção e consulta a órgãos atuantes na área da violência doméstica (Aron, 1991).

A experiência de grupo de encontro, descrita neste artigo, insere-se como intervenção terciária, dentro do Programa, realizada no consultório psicológico da universidade.

\section{Pressupostos teóricos do grupo de encontro}

O grupo de encontro é uma das modalidades do grupo vivencial que, segundo Fonseca (1988), tem como característica fundamental o fato de que

o facilitador não tem nenhum programa a priori para o grupo. O que interessa à sua proposta é que as pessoas, as realidades existenciais presentes no grupo, efetivamente se encontrem. Que se descubram, que se criem e recriem ativamente, a partir da espontaneidade da dinâmica das relações, da multiplicidade de suas perspectivas pessoais e coletivas, tanto em termos da subjetividade, comportamentos e ações dos segmentos deste e das pessoas individuais (p. 20).

O termo facilitador é utilizado para denominar o profissional que possibilitará que o processo do grupo se desenvolva, partindo do principio de que este profissional não irá dirigir ou determinar o processo do grupo, mas tão somente proporcionar condições facilitadoras para o seu desenvolvimento - daí a denominação.

Esta forma de trabalho com grupos baseia-se no axioma básico da terapia de grupo centrada na Pessoa, proposta por Carl Rogers: a 
tendência formativa. Para Wood (1983), "o objetivo (e a arte) da terapia de grupo é facilitar a criação de um clima em que a tendência formativa possa expressar-se livremente em cada pessoa e no grupo de pessoas" (p. 49).

A tendência formativa, que se refere aos grupos, vincula-se, por sua vez, ao conceito basilar da abordagem centrada na pessoa: a tendência atualizante. Este conceito é desenvolvido por Rogers (1976) a partir de sua "visão de homem como um ser digno de confiança" (p. 16), pois, segundo ele, não é que esta abordagem dê poder à pessoa, ela simplesmente não a elimina. Refere-se aí ao poder pessoal que ele acredita existir naturalmente em cada ser humano.

Desde 1951, em A terapia centrada no cliente, aparecem as primeiras referências rogerianas a uma "tendência direcional positiva". Rogers (1976) a descreve como "um fluxo subjacente de movimento para uma realização construtiva de suas possibilidades intrínsecas (...) uma tendência natural para o desenvolvimento completo" (p.17), ou ainda como "uma tendência inerente para desenvolver todas as suas (da pessoa) potencialidades e para desenvolvê-las de maneira a favorecer sua conservação e seu enriquecimento" (Rogers, 1977, p. 159). Desta forma, tanto a metodologia de trabalho proposta pelo grupo de encontro quanto a teoria de Carl Rogers como um todo, têm como fundamento o conceito de tendência atualizante, visto que, para Rogers (1978), "o grupo é semelhante a um organismo, possuindo o sentido de sua própria direção” (p. 52).

Rogers (1978) define o grupo de encontro como um método de trabalho que "pretende acentuar o crescimento pessoal e o desenvolvimento e aperfeiçoamento da comunicação e relações interpessoais, através de um processo experiencial" (p. 14). Com relação aos "frutos" deste tipo de trabalho, Rogers (1978) assinala que

uma das evoluções mais freqüentes é o sentimento de confiança, que começa lentamente a construir-se e também um sentimento de calor humano e simpatia pelos outros membros do grupo (...). Assim, num grupo destes, o indivíduo acaba por conhecer a si próprio e a cada um dos outros mais completamente do que lhe é possível nas relações habituais ou de trabalho. Toma conhecimento profundo 
dos outros membros e do seu eu interior, o eu que, de outro modo, tende a esconder-se por detrás da fachada. A partir daí, relaciona-se melhor com os outros, não só no grupo mas também, mais tarde, nas diferentes situações da vida de todos os dias (p. 19).

Segundo Rogers (1978), “os grupos de encontro conduzem a uma maior independência pessoal, a menos sentimentos escondidos, maior interesse em inovar, maior imposição à rigidez institucional (...) Eles produzem a mudança construtiva (...) só podem florescer em um ambiente essencialmente democrático" (p. 23). Neste sentido, o papel do facilitador não será de dirigir o grupo, impor regras ou normas, mas de viabilizar o processo de desenvolvimento do grupo, dentro do seu próprio ritmo. Desta forma, o tema tratado entre os participantes do grupo de encontro será o emergente, trazido pelo grupo. As intervenções realizadas pelo facilitador visarão o encontro entre os participantes e suas realidades existenciais. No caso desta experiência, a hipótese foi de que o tema emergente seria, espontaneamente, a violência intrafamiliar, problemática comum das participantes.

\section{Grupo de encontro com mulheres vitimas de violência intrafamiliar}

As justificativas para a introdução da atividade de grupo de encontro no "Programa de Maus Tratos a Mulheres" foram:

1. o grupo de encontro é um modelo de intervenção psicológica mais breve, mais imediato, que se utilizou dos recursos da rede social no caso as próprias mulheres - para desenvolver suas potencialidades no sentido de alcançar o bem estar psicossocial;

2. buscar a utilização dos próprios recursos do grupo, enquanto parte da rede social, da comunidade, foi coerente com o objetivo do Programa;

3. o grupo de encontro possibilitou o atendimento a um número maior de mulheres, com menores custos para o Programa;

4. tratou-se de uma oportunidade de aprendizagem para os alunos em estágio no Consultorio: vivenciar o papel de facilitador de grupo com a supervisão correspondente.

O seguintes aspectos do grupo de encontro o indicaram para o "Programa de Maus Tratos a Mulheres": 
1. teve como objetivo o encontro, no sentido existencial do termo (Buber, 1979). No caso das mulheres vítimas de violência doméstica, o encontro proporcionou o apoio necessário, a partir das problemáticas similares;

2. possibilitou a superação da situação de violência intrafamiliar e busca de bem estar psicossocial a partir do surgimento de uma rede de apoio e da troca de experiências entre as participantes;

3. o papel dos facilitadores foi unicamente o de facilitar o processo de auto-ajuda entre as participantes. O grupo se utilizou de seus próprios recursos, provenientes do encontro entre participantes;

4. o foco nesta forma de intervenção psicológica ocorreu no nível da comunicação entre os participantes e do contato inter-humano. A facilitação do processo de comunicação buscou o fortalecimento das mulheres para aprofundamento da problemática comum: a violência no lar;

5. a facilitação visou o desenvolvimento da autonomia do grupo e de cada participante individualmente. Esta autonomia é essencial no caso das mulheres que se submetem a situações de violência intrafamiliar;

6. a partir de uma fundamentação teórica fenomenológica-existencial, o grupo de encontro focalizou a questão da responsabilidade existencial e da capacidade de opção do ser humano a partir de seu potencial de desenvolvimento (Moreira, 1990, 1992; Moreira, Saboia, Beco \& Soares, 1995; Rogers, 1975, 1978; Sartre \& Ferreira, 1970). No caso das mulheres maltratadas, o processo de responsabilização em si é essencial para o desenvolvimento da autonomia necessária para assumir e confrontar a violência;

7. o fato de se tratar de uma modalidade de intervenção em grupo ampliou as possibilidades de trabalhar o foco: a violência. Por um lado, a heterogeneidade das histórias de vida e, por outro, os aspectos comuns, proporcionaram o intercâmbio na própria rede social, a comunidade de origem;

8. a troca de experiências entre as mulheres propiciado por sua participação no grupo foi enriquecedor por sua organicidade, na medida em que elas são as próprias integrantes da comunidade e trazem em si mesmas os recursos para sair da situação de violência doméstica; 
9. o grupo de encontro se propôs a ser uma intervenção temporária, breve, com a função de mobilizar as potencialidades no sentido do bem estar psicossocial;

10. esta modalidade pôde ser utilizada como uma forma de intervenção precoce, com fins de evitar uma demanda de psicoterapia dentro do modelo tradicional de tratamento (Aron, 1991).

\section{Método}

Foram realizadas sete sessões durante sete semanas, de duas horas de duração, gravadas em vídeo através de vidro unidirecional na sala de espelho do consultório da Pontifícia Universidad Católica de Chile. O número de participantes foi de oito mulheres, encaminhadas a partir da primeira entrevista no hospital da comunidade ou de psicoterapia individual no Consultorio. Trabalharam como facilitadoras uma psicoterapeuta e uma aluna estagiária. Uma segunda aluna estagiária ficou encarregada da filmagem com fins de discussão clínica posterior.

Foram selecionadas quatro sessões para efeito de análise. Duas (a segunda e a terceira) foram excluídas em virtude de problemas técnicos na gravação.

As etapas para estudar a temática da violência doméstica nas sessões de grupo de encontro realizadas foram seguintes:

a. Gravação das sessões em vídeo.

b. Cada sessão foi assistida posteriormente, sendo anotados os temas que iam emergindo e como foram trabalhados no grupo.

c. Para fins didáticos, de apresentação clínica junto à equipe do Programa, todas as sessões foram divididas em três fases: 1) aquecimento; 2) desenvolvimento do processo grupal; e 3) encerramento. Esta divisão diz respeito aos temas emergentes, ou seja, em linhas gerais, observou-se que em todas as sessões ocorria o seguinte:

Fase de aquecimento: Os conteúdos que surgiram nesta fase inicial da sessão eram mais gerais, relativos ao setting, à chegada de uma nova participante no grupo, ao papel do grupo etc. Nas últimas 
sessões, esta fase foi bem mais curta. As participantes não sentiam mais a necessidade de um aquecimento, indo diretamente a conteúdos que lhes interessava compartilhar.

Fase de desenvolvimento do processo grupal: Os conteúdos nesta fase passavam a ser de ordem mais pessoal. As participantes, neste momento, pareciam soltar-se mais, sentindo-se mais livres para compartilhar suas histórias, seus sofrimentos, suas esperanças.

Fase de encerramento: Nesta fase, uma das facilitadoras assinalava o final da sessão, o que não necessariamente significava um encerramento imediato, mas uma fase de término. Uma das características desta experiência foi uma dificuldade de encerrar verificada na maioria das sessões. As mulheres continuavam a falar, trazendo seus conteúdos. Neste momento, as facilitadoras insistiam sobre a finalização dentro do horário contratado, trabalhando, assim, para a delimitação do espaço do grupo, cuja determinação de início e fim é fundamental na medida em que o que se passa nesse intervalo emergirá espontaneamente. A estrutura do enquadramento possibilita a desestruturação do processo construído pelo próprio grupo.

O procedimento utilizado para esta análise consistiu em re-escrever o texto nativo da pesquisa várias vezes, até se chegar a uma síntese (Amatuzzi, 1993). Trata-se da transcrição original do videotape da sessão, incluindo a descrição tanto do que é verbalizado pelas participantes como dos diversos movimentos observados, tais como mudança de lugar por parte de uma participante, disposição do grupo, silêncios etc.

Este procedimento é similar ao descrito por Giorgi (1985), contendo quatro passos: 1) leitura da descrição total, visando a obtenção de um sentido geral; 2) discriminação de unidades de significado em uma perspectiva psicológica, focalizando o fenômeno pesquisado; 3) transformação de expressões cotidianas em linguagem psicológica, com ênfase no fenômeno estudado e; 4) síntese da transformação das unidades de significado em uma descrição consistente da estrutura psicológica do fenômeno apreendido.

Nesta pesquisa, foi utilizado um método similar para a análise de dados, desdobrado em três passos: (a) registro do texto nativo dos 
temas das sessões; (b) reescrita dos temas das sessões e; (c) organização dos temas das sessões, detalhados a seguir.

\section{Resultados e Discussão}

\section{O texto nativo dos temas das sessões}

Este texto refere-se a tudo o que foi anotado sobre cada sessão, quando assistida em vídeo. Foram anotadas as verbalizações de todas as participantes, a descrição do processo de facilitação por parte do grupo e das facilitadoras com respeito aos vários temas emergentes e os eventuais movimentos do grupo observados no videotape.

A divisão em fases - aquecimento, desenvolvimento grupal $e$ encerramento - foi feita a posteriori, isto é, após a redação do texto nativo, que constou em escrever espontaneamente todos os temas, na ordem em que eles iam aparecendo no filme de cada sessão. Tendo em vista o volume deste material, ele não se encontra transcrito neste artigo.

\section{Reescrevendo o tema de cada sessão}

Neste momento da análise, o texto nativo foi reescrito resumidamente por sessão, da seguinte forma:

Sessão 1: Setting, gravação das sessões para efeito de pesquisa, expectativas, papel do grupo como apoio, importância do psicólogo, motivo de estar ali, a não submissão à violência doméstica, a denúncia como estratégia para parar a violência, a vergonha, a necessidade de autovalorização, repetição do processo de espancamento entre as participantes, tratamento para os homens, proposta de grupo terapêutico para os homens espancadores, importância da publicidade a respeito da necessidade de superação da violência intrafamiliar.

Sessão 4: Papel do grupo na vida das participantes, solicitação de participação ativa por parte de todas as mulheres do grupo, resistência a buscar ajuda, acolhida ao sofrimento da companheira, a religião como apoio para seguir adiante.

Sessão 5: Estabelecimento de rede social, a necessidade da mulher de trabalhar fora de casa, segurança financeira x espancamento, mau trato psicológico, violência sexual, efeito terapêutico de com- 
partilhar com outras mulheres que passam por situações similares, dinâmica do grupo, diferença de classes sociais entre as participantes, tentativa de armar uma rede social entre as mulheres participantes do grupo, luta pelo final do grupo versus surgimento de rede social de apoio entre as mulheres na própria comunidade em que vivem as participantes.

Sessão 6: Desejo das participantes de assistir aos filmes das sessões, fim do grupo, contatos posteriores com o Programa, ineficiência do grupo, importância de ir ao juiz, aspectos legais, mulher como vítima, herança de comportamentos de violência familiar, a não submissão da mulher, importância da denúncia, autovalorização, efeito terapêutico de compartilhar as fantasias sexuais, positividade x pessimismo, rede social, atuação civilizada do homem, ensaios de rede social, queixas, progressos do grupo, curiosidade das participantes quanto à terapia, luto, couraça contra os homens em geral, medo do homem, medo do juiz.

\section{Temas relacionados a violência intrafamiliar}

Finalmente, foram levantados os temas surgidos em todas as sessões:

- necessidade fundamental de que a mulher não se submeta à violência doméstica

- a denúncia como estratégia de mudança

- a vergonha

- necessidade de autovalorização

- repetição do processo de espancamento na história familiar

- esperança de que a gravidez pare o espancamento

- visão dos homens como doentes, necessitados de tratamento

- importância da necessidade de superação da violência

- a religião como apoio

- necessidade do estabelecimento de rede social

- necessidade da mulher de trabalhar fora do lar

- segurança e independência financeira $\mathrm{x}$ espancamento

- mau trato psicológico

- violência sexual

- aspectos legais da violência familiar

- couraça contra os homens 
Os resultados organizados conforme as etapas de análise acima descritas, mostraram que foi muito alto o índice de temas emergentes no grupo sobre violência intrafamiliar. Além desta temática, só surgiram outras relacionadas à própria dinâmica do grupo, tais como inclusão de outras participantes, freqüência às sessões, papel do grupo na vida das participantes, papel das facilitadoras etc. Vale lembrar o fato de que o grupo foi selecionado a partir da situação de violência, isto é, de mulheres que buscaram algum tipo de atendimento no hospital da comunidade ou nos outros pontos de identificação dos casos de violência doméstica.

Pôde-se observar que alguns conteúdos emergiram repetidamente no grupo. Entre estes, a necessidade de estabelecimento de uma rede social foi o mais freqüente. Pode-se pensar que esta alta freqüência esteja relacionada, também, ao final eminente do grupo, que tinha um contrato fechado de sete sessões. Outro aspecto importante é que na sexta sessão (a penúltima) os temas que emergem no grupo são em sua maioria repetidos, com diferentes nuanças, evidentemente. Pode-se disso inferir o seguinte: (a) o grupo já estava chegando ao seu final e o processo de repetição ocorre no sentido de aprofundar conteúdos já trabalhados, não emergindo conteúdos novos; (b) os temas mais importantes relacionados à violência doméstica da mulher são, de fato, os que surgiram nas sessões ao longo desta experiência de grupo de encontro.

Os resultados mostram que a hipótese inicial foi comprovada, ou seja, a partir do momento em que se reuniram mulheres vítimas de violência intrafamiliar para uma experiência de grupo de encontro, o conteúdo emergente, compartilhado e aprofundado nas sessões girou, basicamente, em torno da temática relacionada à situação de violência doméstica vivida pela mulher. Mais que isto, nesta experiência o conteúdo emergente tratou dos temas mais importantes relativos à violência e às estratégias de sua superação.

O grupo de encontro mostrou-se indicado para o Programa de Maus Tratos a Mulheres, tal como pôde ser observado pelos resultados da pesquisa realizada: o conteúdo emergente no grupo foi, basicamente, relacionado à situação de violência intrafamiliar e às estratégias de sua superação. 
Na última sessão (a sétima), foi feita uma avaliação com as participantes, que definiram a experiência de maneira positiva, sentidose mais fortes e preparadas para a superação da situação de mulher vítima de violência intrafamiliar. Esta última sessão, contou, inclusive, com uma festa surpresa, organizada pelo próprio grupo, para a qual cada participante levou algo. Isto demonstra o aprofundamento da coesão e autonomia grupal.

Uma das participantes não se sentiu suficientemente forte e autônoma ao final dos dois meses, o que foi avaliado com as facilitadoras e o grupo na última sessão. Esta participante não havia conseguido realizar mudanças significativas das estratégias de conter a violência no seu lar. Foi, então, encaminhada para psicoterapia individual. Este caso mostra que a situação da mulher vítima de violência intrafamiliar pode ser mais complexa que uma problemática psicossocial, referindo-se a aspectos mais profundos, relacionados à própria dinâmica intrapsíquica da mulher e a uma relação interpessoal conjugal patológica. Nestes casos, haveria a necessidade de encaminhamento para psicoterapia individual. Vale sublinhar, no entanto, que nesta experiência não foi isto o que ocorreu na maioria dos casos. Para a maior parte das participantes deste grupo de encontro esta experiência foi avaliada como significativa e suficientemente transformadora.

Não se sabe se estes efeitos positivos irão se manter através do tempo. Para pesquisar este aspecto, a equipe do Programa de Maus Tratos da Pontifícia Universidad Católica de Chile pretende fazer contatos posteriores com as mulheres. $\mathrm{O}$ estabelecimento da continuidade da rede social (tema muito presente nas sessões) entre as participantes somente poderá ser avaliado na pesquisa prevista para um futuro próximo. Vale ressaltar, no entanto, que na última sessão, as participantes decidiram continuar se encontrando nas terças-feiras, no mesmo horário do grupo. Um problema que se configurou foi o local para este encontro, o que possivelmente se transformou em uma variável que dificultou a continuidade. Experiências anteriores com grupo de encontro mostram que o mais provável é que se mantenham redes sociais entre dois ou três participantes, ou seja, de subgrupos e não do grupo como um todo. Caso isto ocorra nesta 
situação específica, já será suficiente para funcionar como fonte de apoio entre as mulheres.

Pode-se observar que o encaminhamento para esta modalidade de atendimento deve ser realizado após duas ou três sessões individuais. Mulheres que foram encaminhadas diretamente da primeira entrevista no hospital da comunidade não compareceram ao grupo, desistiram de continuar o tratamento indicado. Este fato se explica pela ambigüidade própria nos casos de violência conjugal: a mulher quer e não quer denunciar o marido, assumindo a situação de violência perante a polícia, a família, a sociedade. Desta forma, as duas sessões iniciais parecem proporcionar às mulheres uma maior consistência em sua decisão de parar a violência.

Apesar de o grupo de encontro ter como pressuposto básico a autonomia dos participantes e o autodesenvolvimento do processo grupal, o papel do facilitador é fundamental. Nesta experiência, ficou explícita a importância das facilitadoras enquanto especialistas em Psicologia, o que pareceu ser um fator que propiciou a confiança das participantes para investirem e se entregarem ao processo. Nesta mesma linha, o próprio nome da Pontificía Universidad Católica de Chile apareceu como suporte, estrutura confiável, sendo para as participantes um privilégio serem "cuidadas" por profissionais do Consultorio. Neste sentido, a idéia do grupo de auto-ajuda na comunidade, sem a presença de especialistas é algo que deverá ser avaliado. É possível que possa vir a ocorrer a partir de processo espontâneo de estabelecimento de redes sociais em subgrupos, oriundos do grupo de encontro.

Um aspecto que ficou muito nítido nesta experiência foi a atuação das "facilitadoras naturais", ou seja, participantes que visivelmente tinham uma participação facilitadora no grupo, fato que ocorre comumente nos grupos de encontro. No caso deste grupo com o foco na violência doméstica, a heterogeneidade das participantes propiciou que isto ocorresse, fato fundamental para o sucesso da experiência. Em outras palavras, as intervenções facilitadoras das próprias mulheres tiveram muito peso porque foram honestas e abertas, o que, como as próprias mulheres enfatizaram, não é possível em 
outros ambientes sociais, dentro da própria comunidade, onde a violência sempre é tão escondida.

Ainda um aspecto que vale ser ressaltado é a importância da divulgação do Programa enquanto uma estratégia para parar a violência. O fato de se realizarem entrevistas na televisão e publicações nos jornais, propicia a mudança da visão pela sua condição de mulher submissa. Aprende-se e informa-se sobre a violência intrafamiliar como algo a ser combatido e extinto, como parte dos direitos humanos.

Finalmente, esta experiência mostrou também a dificuldade neste tipo de trabalho em virtude da descontinuidade, das faltas, o que foi trabalhado dentro do processo de grupo. $\mathrm{O}$ fato de ser mantido o grupo aberto, por decisão própria, fez com que cada sessão fosse um "recomeço", com a presença de novas participantes. De fato, só quando o grupo se fechou, mantendo as mesmas participantes, é que o processo foi aprofundado, com o intercâmbio mais íntimo. Trabalhar com grupos fechados coloca-se, então, como uma recomendação importante para experiências posteriores de grupo, na medida em que o objetivo do grupo de encontro não é funcionar unicamente como fator de alívio. Não se trata de contar o que acontece, mas de intercambiar as emoções próprias da experiência de violência no lar, utilizando o grupo como um espaço seguro para o aprofundamento destas emoções, no sentido de buscar parar, definitivamente, a situação de violência intrafamiliar.

Pode-se concluir que a análise desta experiência contribui para a utilização do grupo de encontro como modalidade de intervenção na área de saúde pública. Incentiva-se aqui sua realização nesta área, bem como futuras pesquisas que dêem continuidade ao presente estudo.

\section{Referências}

Amatuzzi, M. (1993). O sentido que faz sentido: uma pesquisa fenomenológica no processo terapêutico. Psicologia: Teoria e Pesquisa, 9, 1-21.

Aron, A. M. (1991). Un modelo de salud mental comunitária en Chile. In F. Lolas, R. Florenzando, G. Gymart \& C. Trejo (Orgs.), 
Ciencias sociales y medicina: perspectivas lationamericanas (pp. 89-100). Santiago: Editorial Universitária.

Buber, M. (1979). Eu e tu. São Paulo: Cortez e Moraes.

Fonseca, A. (1988). Grupo, fugacidade, ritmo e forma: processo de grupo e facilitação na psicologia humanista. São Paulo: Ágora.

Giorgi, A. (1985). Sketch of a psychological phenomenological method. In A. Giorgi (Org.), Phenomenology and psychological research (p. 8-22). Pittsburg: Dusquesne University Press.

Moreira, V. (1990). Liberdade em Carl Rogers. Educação em Debate, 19/20, 89-98.

Moreira, V. (1992). O conceito de pessoa na teoria de Carl Rogers. Revista Brasileira de Pesquisa em Psicologia, 4, 7-18.

Moreira, V., Saboia, A., Beco, L., \& Soares, S. (1995). Psicoterapia fenomenológico-existencial: aspectos teóricos de la práctica clínica con base en las competencias. Psykhe, 4, 121-129.

Rogers, C. (1975). A terapia centrada no cliente. São Paulo: Martins Fontes.

Rogers, C. (1976). Sobre o poder pessoal. São Paulo: Martins Fontes.

Rogers, C. (1977). Definição das noções teóricas. In C. Rogers \& M. Kinget (Orgs.), Psicoterapia e relações humanas (v. I., pp. 157180), Belo Horizonte: Interlivros.

Rogers, C. (1978). Grupos de Encontro. São Paulo: Martins Fontes.

Sartre, J. P., \& Ferreira, V. (1970). O existencialismo é um humanismo. Lisboa: Editorial Presença.

Wood, J. (1983). Terapia de grupo centrada na pessoa. In C. Rogers, J. Wood, M. Miller \& A. Fonseca (Orgs.), Em busca de vida (pp. 45-87). São Paulo: Summus. 
Virginia Moreira é psicóloga, doutora em Psicologia Clínica, é Professora Associada e coordenadora acadêmica da Escuela de Psicología da Universidad de Santiago de Chile, sócia titular, especialista em psicoterapia e supervisora credenciada pela Sociedad Chilena de Psicología Clínica. Endereço para correspondência: Av. Ecuador 3650, Santiago, Chile. Telefax: ++56(2)7761986.

E-mail: vmoreira@lauca.usach.cl. 